\title{
Is the Head Louse, Pediculus humanus capitis Vector of Human Diseases?
}

\section{Kosta Y. Mumcuoglu*}

Department of Microbiology and Molecular Genetics, The Kuvin Center for the Study of Infectious and Tropical Diseases, The Hebrew University - Hadassah Medical School, Jerusalem, Israel

Head lice are hematophagous ectoparasitic insects, specific to humans and spending their entire life on their host. Humans are parasitized by two species of lice: The human louse, Pediculus humanus, which appears in two ecotypes, the head louse, Pediculus humanus capitis and the body louse, Pediculus humanus humanus. The second species is the pubic louse, Pthirus pubis. Infestation with lice can cause dermatitis and pruritus and sometimes secondary infections and lymphadenopathy.

Since the early years of the $20^{\text {th }}$ century, it has been known that body lice are vectors of three pathogenic bacteria: a) Rickettsia prowazekii, the agent of epidemic typhus; b) Borrelia recurrentis, the agent of louseborne relapsing fever; and c) Bartonella quintana, the agent of trench fever. Lately, body lice were also shown to be vectors of Acinobacter baumannii, an aerobic Gram-negative bacterium, which is resistant to most antibiotics [1].

As opposed to body lice, the vectorial ability of head lice remains quite controversial. 39 head lice were fed on a rabbit that had been injected intravenously with a virulent strain of $R$. prowazekii [2]. Five days after infection, 16 of them were still alive and were allowed to feed on a human volunteer. Between days 5 and 9, 13 head lice were dead or moribund and all of them were positive by IF for $R$. prowazekii. The three surviving head lice were also positive.

Head and body lice collected from homeless people in San Francisco, California (USA) were tested for B. quintana. It was found that $33.3 \%$ of body lice-infested persons and $25 \%$ of head lice-infested persons had lice infected with B. quintana strain Fuller [3]. B. quintana was found in $7 \%$ of head lice and in $18 \%$ of body lice isolated from naturally infested individuals in Ethiopia [4]. In head and body lice collected from 30 Nepalese children (including 11 cases of double infestation), B. quintana DNA sequences were detected in both head and body lice from two children as well as in body lice derived from two additional children [5]. In addition, the DNA of this pathogen was also detected in head louse eggs collected from a homeless man in Ethiopia [6].
Although head lice can be readily infected with $R$. prowazekii and $B$. quintana and later disseminate these virulent organisms in their feces, thus having the potential to be vectors of these pathogens under optimal epidemiologic conditions, e.g. during outbreaks of epidemic typhus, no reports can be found that in the absence of body lice, head lice could act as vectors under field conditions. In experimental work conducted with head and body lice, the humoral immune response of both lice, following bacterial challenge was examined and it was shown that both exhibited an increased immune response to Staphylococcus aureus but little to Escherichia coli. However, head lice exhibited a significantly higher phagocytotic activity against $E$. coli than body lice, suggesting that the reduced phagocytotic activity in body lice could be responsible, in part, for their increased vector competence [7].

It is concluded that head lice are poor biological vectors of human diseases and accordingly of little relevance from the epidemiologic point of view of these diseases.

\section{References}

1. Houhamdi L, Raoult D (2006) Experimental infection of human body lice with Acinetobacter baumannii. Am J Trop Med Hyg 74: 526-531.

2. Murray ES, Torrey SB (1975) Virulence of Rickettsia prowazeki for head lice Ann N Y Acad Sci 266: 25-34

3. Bonilla DL, Kabeya H, Henn J, Kramer VL, Kosoy MY (2009) Bartonella quintana in body lice and head lice from homeless persons, San Francisco, California, USA. Emerg Infect Dis 15: 912-915.

4. Cutler S, Abdissa A, Adamu H, Tolosa T, Gashaw A (2012) Bartonella quintana in Ethiopian lice. Comp Immunol Microbiol Infect Dis 35: 17-21.

5. Sasaki T, Poudel SK, Isawa H, Hayashi T, Seki N, et al. (2006) First molecular evidence of Bartonella quintana in Pediculus humanus capitis (Phthiraptera: Pediculidae), collected from Nepalese children. J Med Entomol 43: 110-112.

6. Angelakis E, Diatta G, Abdissa A, Trape JF, Mediannikov O, et al. (2011) Altitude-dependent Bartonella quintana genotype $C$ in head lice, Ethiopia. Emerg Infect Dis 17: 2357-2359.

7. Kim JH, Min JS, Kang JS, Kwon DH, Yoon KS, et al. (2011) Comparison of the humoral and cellular immune responses between body and head lice following bacterial challenge. Insect Biochem Mol Biol 41: 332-339.
${ }^{*}$ Corresponding author: Mumcuoglu KY PhD, Department of Microbiology and Molecular Genetics, The Kuvin Center for the Study of Infectious and Tropical Diseases, The Hebrew University - Hadassah Medical School, Jerusalem, Israel, E-mail: kostam@cc.huji.ac.il

Received November 18, 2012; Accepted November 27, 2012; Published November 29, 2012

Citation: Mumcuoglu KY (2013) Is the Head Louse, Pediculus humanus capitis Vector of Human Diseases? J Trop Dis 1: e101. doi:10.4172/29-891X..1000101

Copyright: ( 2013 Mumcuoglu KY. This is an open-access article distributed under the terms of the Creative Commons Attribution License, which permits unrestricted use, distribution, and reproduction in any medium, provided the original author and source are credited. 